\title{
Compensation in exploited marine fish communities on the Scotian Shelf, Canada
}

\author{
Nancy L. Shackell*, Kenneth T. Frank \\ Department of Fisheries and Oceans, Ocean Sciences Division, Bedford Institute of Oceanography, PO Box 1006, Dartmouth, \\ Nova Scotia B2Y 4A2, Canada
}

\begin{abstract}
We evaluated the temporal dynamics of the aggregate groundfish community, further decomposed into functional groups, individual species abundances, and health indicators, from adjacent management units on the Scotian Shelf. On the colder, eastern half of the shelf, several species collapsed in the early 1990s, while, on the western half, no such collapses were evident despite similar exploitation regimes. The decline in the eastern aggregate biomass was influenced by a decline in average body size, which was interpreted as a past integrator of temperature and size-selective fishing. Biomass of 3 out of 4 functional groups declined in the east; 3 out of 4 groups increased in the west. Some species from the east appear to be slowly compensating, but not enough to counter the decline in aggregate biomass. Species inhabiting the warmer western region show strong evidence of compensation. In effect, warmer waters allow potential compensating species to increase at a faster rate. Quantitative measures of functional group temporal stability revealed no differences between areas; therefore, neither area can be considered stable. Physiological condition declined in many species in both regions. Species that increased in the west, or had slower rates of decline, had higher levels of condition than eastern populations. With the exception of cod in the western region, species growth rates declined in both areas. Although the west appears more stable, it is following a similar, but protracted trajectory, to that found in the east. The protracted response in the west may be due to higher demographic rates in warmer waters. To foster resilience in the western area, we should address the rapid pace of new fisheries, effects of size-selective mortality, and the diminishing number of natural refugia.
\end{abstract}

KEY WORDS: Fishing effects · Trophic control · Compensatory dynamics · Species evenness · Growth rate $\cdot$ Condition index $\cdot$ Large-bodied marine fish

\section{INTRODUCTION}

Historically, the pattern of exploitation of natural resources has been one of excessive depletion, associated with the growth of human populations and technological capacity (reviewed in Ehrlich 2000). More recently, the rapid, post-World War II development of industrialized fisheries has greatly increased fishing pressure and has led to numerous recent declines in large-bodied predators around the globe (e.g. Fu et al. 2001, Pauly et al. 2002, Myers \& Worm 2003, Lotze \& Milewski 2004, Bundy 2005). Removal of large-bodied predators can result in community change, either through competitive or predator release, which is occasionally further modified by climatic effects (e.g. Swain
\& Sinclair 2000, Myers \& Worm 2003, Dulvy et al. 2004, Frank et al. 2005, Heath 2005, Ward \& Myers 2005, Levin et al. 2006). A troubling feature of many modernday collapses is that many populations of large predators are not recovering, even though fishing mortality has been greatly reduced (Hutchings \& Reynolds 2004). The proposed causes for lack of recovery are manifold, but a growing body of research that has focused on changes in trophic structure and function, resulting from depletion of top-predators, is providing new insights into the failed recovery of predator populations (Frank et al. 2006).

Productivity at higher trophic levels in marine ecosystems has generally been considered to be controlled by their base productivity, in other words, they 
are 'resource-controlled' from the bottom-up by the supply of nutrients (Ware \& Thomson 2005). However, with the repeated occurrence of over-fishing of toppredators and an associated increase of their former prey, recent research has shown that many exploited ecosystems may now be 'predator-controlled', and the communities structured by top-down forces (Frank et al. 2005). This has led to a suggestion that predatorprey role reversals may be impeding the recovery of collapsed predator populations.

We have recently attempted to reconcile the relative roles of top-down and bottom-up forcing by examining data from both the northwestern and eastern Atlantic (Frank et al. 2007). Frank et al. (2006) proposed that ecosystem dynamics are generally controlled by the base resource levels, but low-productivity areas may become predator-controlled if those predators are heavily fished. That is, levels of base productivity influence the resilience to over-fishing, through differences in temperature and species diversity. Colder areas with lower levels of base productivity and lower species richness are more likely to show significant ecological changes in response to over-fishing large predators. Conversely, the dynamics of top-predators are less likely to influence lower trophic levels in warmer areas that have higher levels of base productivity and greater species richness. Warmer water would contribute to faster growth rates and shorter generation times, a distinct advantage in a highly exploited system. Higher species richness represents a greater pool of potentially compensating species.

Such relationships derived from large-scale systems necessarily lack detail, but they provide a construct to examine systems of interest in more detail. We took the opportunity to examine 2 adjacent regions on the Scotian Shelf, Canada (see Fig. 1) that have responded differently to similar, sustained, high levels of exploitation. The groundfish community on the eastern half of the Scotian Shelf collapsed in the early 1990s and has failed to recover despite a $10+$ yr cessation of fishing on the traditional groundfish stocks. On the adjacent western Scotian Shelf, the groundfish community continues to support a commercial fishery - a unique situation in Canadian Atlantic waters. The eastern and western areas have also shown pronounced increases in the abundance of small pelagic species. The response is due, in part, to release from predation (Choi et al. 2004). These adjacent regions share a common species composition, and it is generally believed that the warmer waters of the west may confer an increased resilience through increasing growth and demographic rates. In the present paper, we evaluate the temporal patterns in aggregate demersal biomass in relation to variation in fishing intensity, temperature, and body size. We address the question: Does compensation occur more rapidly within functional groups where biomass is more evenly distributed? We show that there are coherent biomass dynamics for several species in the east and west, but compensatory processes are more common in the western area. Indicators of health (condition and growth) were also examined. Both the indicators of health and the decline in slowly maturing animals lead us to conclude that the west is following a similar, but protracted trajectory, to that found in the east.

\section{MATERIALS AND METHODS}

Oceanographic region. The Scotian Shelf spans 42 to $47^{\circ} \mathrm{N}$ latitude and has been divided into eastern $\left(107759 \mathrm{~km}^{2}\right)$ and western $\left(65527 \mathrm{~km}^{2}\right)$ regions (Fig. 1), corresponding to the Northwest Atlantic Fisheries Organization (NAFO) Divisions 4VW and 4X. The divisions serve as management units for the resident commercial fish species and roughly coincide with physical oceanographic and topographical differences (Halliday \& Pinhorn 1990). The east and west are separated by the Emerald basin, which has been considered an impediment to migration of some species. In general, the level of connectivity varies among species and is only known for a few. For example, cod and haddock populations are highly structured (e.g. McKenzie 1956, Zwanenburg et al. 1992, Ruzzante et al. 1996, Shackell et al. 1997), while cusk is believed to be a population that expands from the west to east during periods of increasing abundance (Shackell et al. 2005). In effect, there is no operational, ecosystem-level measure of distinctiveness, but the similarity of species composition reflects their adjacency, while differences in growth rates between east and west reflect the climatological temperature and base productivity differences: the eastern shelf experiences colder bottom temperatures (Fig. 2) and lower base productivity (Frank et al. 2006) than does the western shelf.

Data. The Canadian Department of Fisheries and Oceans has conducted annual, summer research vessel (RV) surveys since 1970 to assess the distribution and abundance of groundfish. A stratified random sampling design is used; 48 strata are defined by depth and geographic location. Within each strata, fish are captured with a standard, Western IIA bottom trawl with a $19 \mathrm{~mm}$ codend liner. The trawl is deployed at a constant speed of 3.5 knots for approximately $30 \mathrm{~min}$, resulting in a swept area of $0.0404 \mathrm{~km}^{2}$ (equal to $1 \mathrm{set}$ ). The number of sets was generally proportional to stratum area. Sampling was conducted around the clock randomly among strata and years during the month of July.

We defined fish functional groups based on maximum body size (www.fishbase.org/search.php) and diet. Diet information from Link \& Almeida (2000) and 


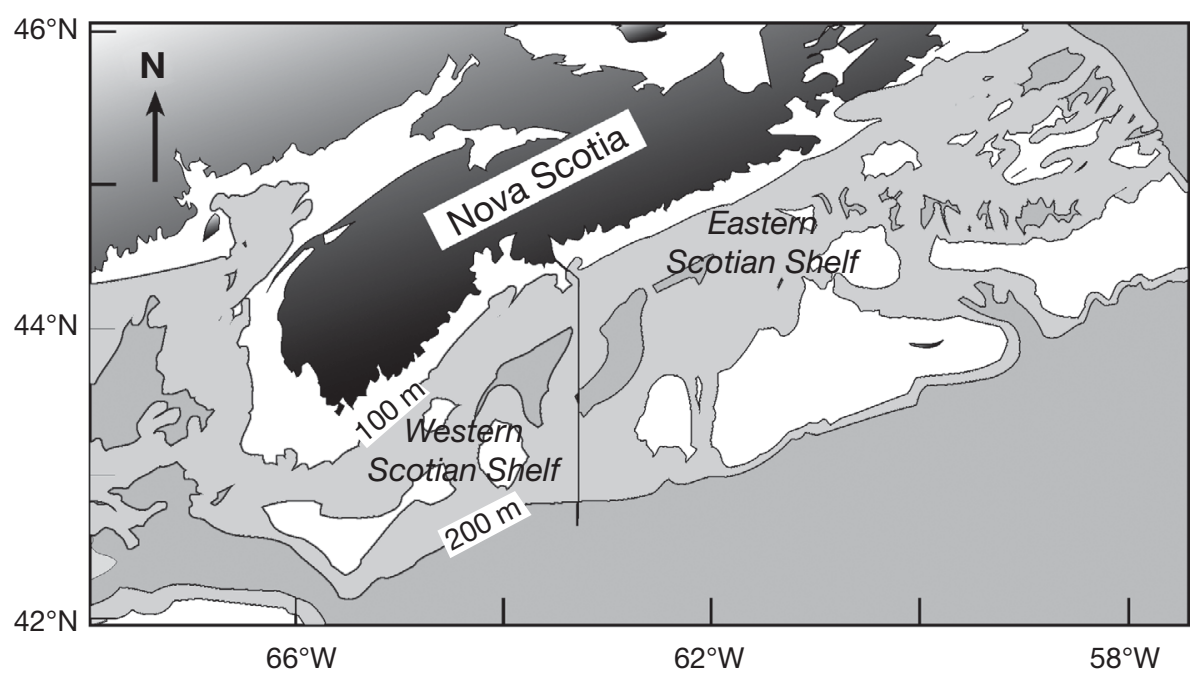

Fig. 1. Scotian Shelf in the northwestern Atlantic

Bundy (2005) was used as a guide to classify each species into trophic guilds. The result was 4 groups (Table 1): medium (>45 and $<79 \mathrm{~cm}$ ) and large (>80 cm) benthivores (consumers of bottom-dwellers), piscivores (consumers of primarily fish), and pelagic predators (consumers of amphipods, euphausids, and fish). These categories are similar to those developed by Link \& Almeida (2000), but have been modified with respect to the classification of generalist feeders. We summed weight $(\mathrm{kg})$ per tow for each species within a group to form an aggregate biomass for each group. In the present paper, we focus on the traditional demersal fish community. Smaller demersal fish (maximum size <46) and planktivores have been treated elsewhere (Choi et al. 2004).

Analyses. We used the $\mathrm{R}$ statistical software, the open-source version of S-PLUS (R Development Core Team 2005; www.R-project.org), for most analyses and Primer 5 software (PRIMER-E Ltd. 2001; www. Primer-e.com/) to calculate species evenness.

Aggregate biomass of demersal species, fishing intensity, and temperature: We explored how demersal species' biomass varied in relation to fish landings and temperature in both regions (Fig. 2). We recognized that the direct effects of fishing and temperature were likely cumulative, but also noted that the aggregate biomass was comprised of a wide range of species with different life histories and that the effects of fishing and temperature may have different lag effects for different species. To simplify the model, we summarized the variability in aggregate biomass as a function of un-lagged (current) fishing intensity and temperature. Aggregate biomass was defined as the sum of weight per tow of all demersal species $>45 \mathrm{~cm}$ in maximum length (www.fishbase.org/search.php). The index of fishing was expressed as the sum of annual groundfish NAFO landings. We used median temperature as recorded during the RV bottom trawl surveys. Mean individual weight was calculated as the total aggregate weight divided by total numbers for each region and included in the model to account for its possible influence on total biomass. Frank et al. (2006) showed that species evenness (as measured by Hill's N1) of the major demersal species complex was comparable between the east and west, and therefore an evenness index was not included in the model.

To explore the relationship of biomass, landings, temperature, and individual weight between regions, we used a generalized additive model (GAM) approach (Hastie \& Tibshirani 1990) that includes estimation of parameters, as well as estimates of the relationship between the response variable and any nonparameterized effects through the use of smoothing techniques, based on penalized regression splines. Our initial analyses indicated that the relationships between biomass, as a response variable and temperature, exploitation, and average body weight were not the same in both regions (i.e. strong interaction terms). Even though the GAM procedure provided in the 'mgcv' package of R (R Development Core Team 2005; www.R-project.org) allowed fitting region-specific covariates into a single model, we decided that the regions were best described separately.

The final model for each region was:

aggregate weight per tow $=$

mean $+\mathrm{s}$ (landings) $+\mathrm{s}$ (median temperature)

$+\mathrm{s}$ (individual weight) + error

where errors were assumed to be log-normally distributed (through the use of a link function) and s( ) repre- 
sents the non-parametric terms that were smoothed iteratively. We fixed the basis dimensions in the full model so that the smoothed components were unpenalized, which yields a better estimate of the level of significance. However, we did not interpret the results solely with respect to the statistical significance. Our primary goal was to explore the pattern of biomass at various levels of the independent variables and to determine whether the areas behaved similarly. We also investigated the use of a lagged term to account for biomass being dependent on biomass from the previous year, but we dropped it to simplify the model, given that our interpretation of the results from both models was similar.

Species diversity/evenness: To estimate total diversity, we used the ECNASAP database (East Coast North American Strategic Assessment Project is a database that contains counts of 200+ individual species from 1970 to 1994; Robert Branton, Department of Fisheries and Oceans, Dartmouth, Nova Scotia B2Y 1A2, Canada). To estimate evenness, we used the RV survey database that contained biomass estimates. We used
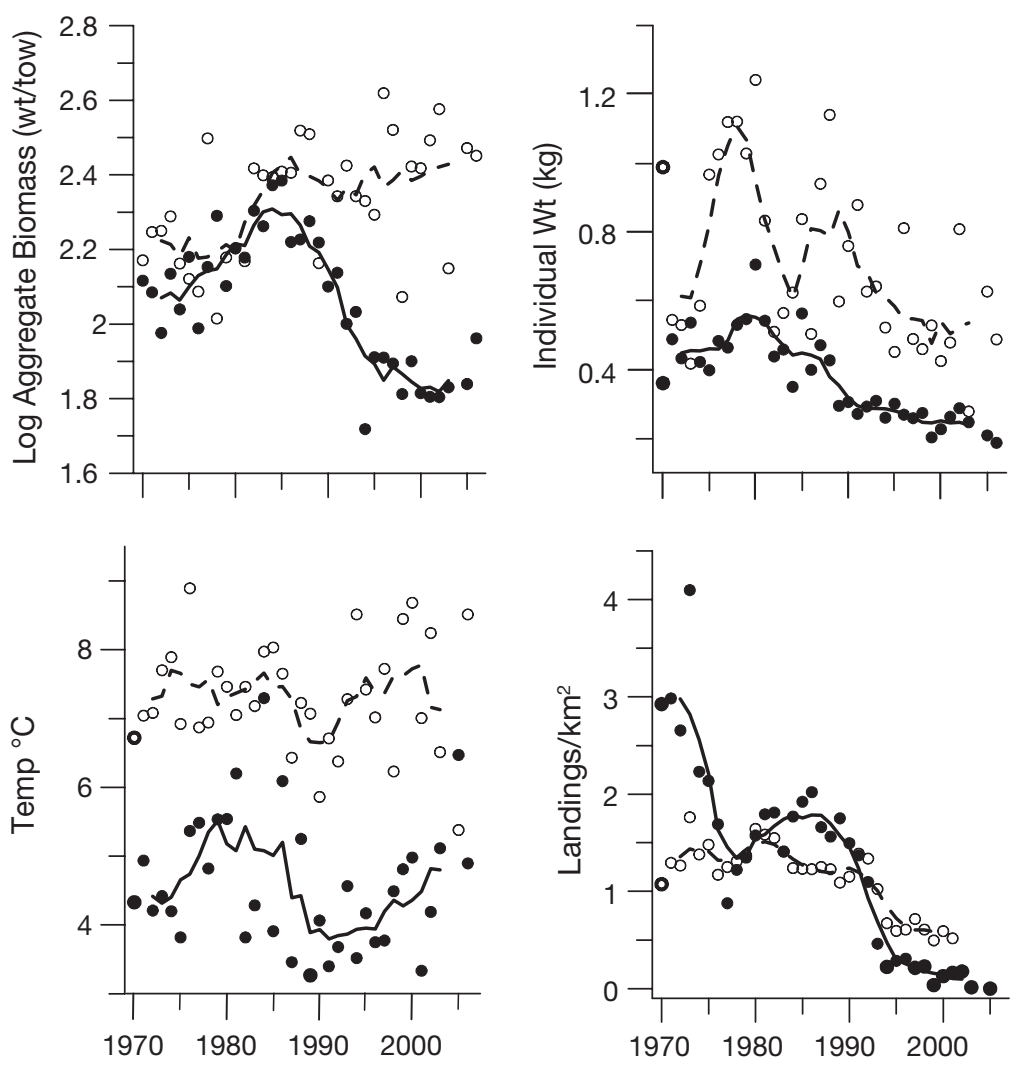

Fig. 2. Aggregate biomass (log weight per tow), individual weight (kg), bottom median temperature, and groundfish landings over time in the eastern $(-, \bullet)$ and western $(---$, o) Scotian Shelf. Lines represent 5 yr running averages. Aggregate biomass values represent the aggregate sum of all demersal fish with a maximum size $>45 \mathrm{~cm}$. Landings represent the sum of commercially exploited groundfish landings
Primer software to calculate Hill's N1, which is an index of diversity/evenness that accounts for proportional biomasses. Higher values of Hill's N1 indicate that biomass is more evenly distributed among species.

Temporal stability: To acquire a sense of functional group stability that incorporated species covariance, we used an index developed by Lehman \& Tilman (2000). They devised a measure of stability that accounts for species interactions by incorporating the covariance among species. Higher levels of stability would occur if negative covariances reduced the denominator in Eq. (2).

$$
T S_{\mathrm{FG}}=\frac{\sum_{i=1}^{n} \operatorname{Mean}\left(S_{i}\right)}{\sqrt{\sum_{i=1}^{n} \operatorname{Var}\left(S_{i}\right)+2 \sum_{i=1}^{n} \sum_{j=1}^{i-1} \operatorname{cov}\left(S_{i} S_{j}\right)}}
$$

where $T S_{\mathrm{FG}}$ is the temporal community stability of a given group, $S_{i}$ refers to mean weight $(\mathrm{kg})$ per tow of species $i, S_{j}$ refers to mean weight $(\mathrm{kg})$ per tow of species $j$, and $n$ is the total number of species within a group. Note the similarity to a commonly used index of temporal stability, the coefficient of variation. The equation above has the advantage of directly measuring the effect of species interaction, or compensation.

Condition and individual growth rates: To investigate the possible differences in fish health between regions, we used predicted weight-at-length from weight/length regressions as a measure of adult fish condition, with a length of $45 \mathrm{~cm}$ chosen as the representative size. We used analysis of covariance where condition was the response variable, year was a covariate, and region was a factor. Data were available for 18 species and were logtransformed prior to analysis. If the interaction term was not significant, implying that the slopes of condition over time were parallel between regions, we reduced the terms to an additive model; a significant effect of year (covariate) within the additive model implies that the slopes exhibited a time trend. A significant effect of region (factor) implies that the mean value of condition differed between the 2 areas (Dalgaard 2002). Size-at-age data were used as a measure of mean growth rate. Unlike condition, size-at-age was available for only 4 species, and we decided against any formal statistical analyses because of the resultant patterns. The data correspond to the eastern Scotian Shelf and the shelf portion of the west. 


\section{RESULTS}

\section{Aggregate biomass of demersal species, landings, and temperature}

Aggregate biomass of demersal species exhibited a divergent trend between the 2 areas: declining in the east and increasing in the west (Fig. 2). Individual weight declined steadily in the east, while, in the west, the decline started later, after a brief increase during the mid-1980s. Initially, landings were 2- to 3 -fold greater in the east; landings have declined since then in both areas. Bottom temperature in the west has been both higher $\left(\sim 2^{\circ} \mathrm{C}\right)$ and more stable than in the east. Eastern temperatures reached a minimum in the early 1990s and have increased slowly since that time.

When eastern aggregate weight per tow was modeled as a function of landings, median temperature, and individual weight, all 3 variables had an effect on aggregate biomass (adjusted $\mathrm{R}^{2}=0.73$; landings $F=$ 4.93, $\mathrm{p}<0.001$, edf $=3$; median temperature $F=5.05$, $\mathrm{p}<0.05$, edf $=2$; individual weight $F=3.15, \mathrm{p}<0.05$, edf $=5$ ). However, no effects of the 3 independent variables, using the same estimated degrees of freedom (edf), were evident when western aggregate biomass was modeled. This can be seen by comparing the vertical spread and confidence intervals of the effect of the smoothed components between east and west (Fig. 3).

In the east, lower levels of biomass were associated with high and low levels of landings. Low biomass at the lowest levels of landings reflects the failure of stocks to recover after their collapse despite restrictions on fishing. When all else was constant, the effect of a decrease in temperature was not a decrease in aggregate weight per tow; weight per tow was only slightly higher at cooler and warmer temperatures. However, note the low number of observations at higher temperature values (Fig. 3). In the east, the effect of individual weight was evident. The vertical spread of the individual effects component was much larger in the east, implying a stronger effect of individual weight on biomass.

\section{Aggregate biomass of functional groups}

Large-bodied benthivores initially declined in both areas, but have shown a recent increase in both regions (Fig. 4), due mainly to haddock (Fig. 5). Piscivores exhibited a divergent trend between east and west (Fig. 4); increases in spiny dogfish in the west were responsible for this difference. Dogfish increased in the east until the mid-1980s and then declined, coincident with the development of cooler waters, which are avoided by dogfish (Fig. 5). Medium benthivores
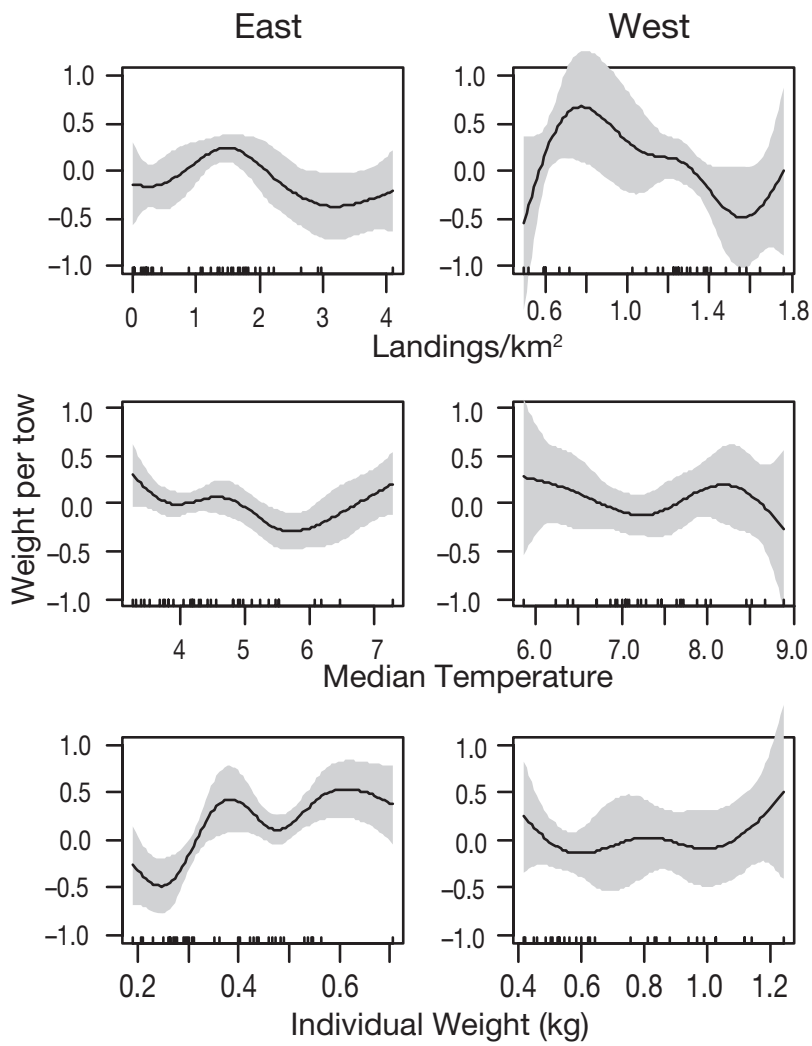

Fig. 3. Effect of smoothed components, adjusting for other factors, on biomass in the east and west. The model was only effective in describing patterns in the east; the west is displayed for comparative purposes. Shaded areas represent $95 \%$ point-wise confidence limits. Tick marks below the curve represent the value of the effect where the observations occurred, and are useful for evaluating the component effect relative to the actual observations

increased in the west due to winter flounder, which also increased in the east, but not enough to compensate for the decline in witch and yellowtail flounder. Interestingly, yellowtail is increasing in the west and declining in the east. The pelagic predator functional group was relatively stable in the west (Fig. 4), due to the persistence of redfish and silver hake, but declined in the east (Fig. 5). In summary, 3 out of 4 functional groups in the eastern Scotian Shelf showed clear declines, whereas no such declines were evident in the west.

\section{Species richness}

From 1970 to 1994, a total of 95 and 94 species were recorded in the east and west, respectively. The east and west had 79 species in common. Those species unique to the east were: longnose eel Synaphobranchus kaupi, horned lanternfish Ceratoscopelus maderensis, Epix- 

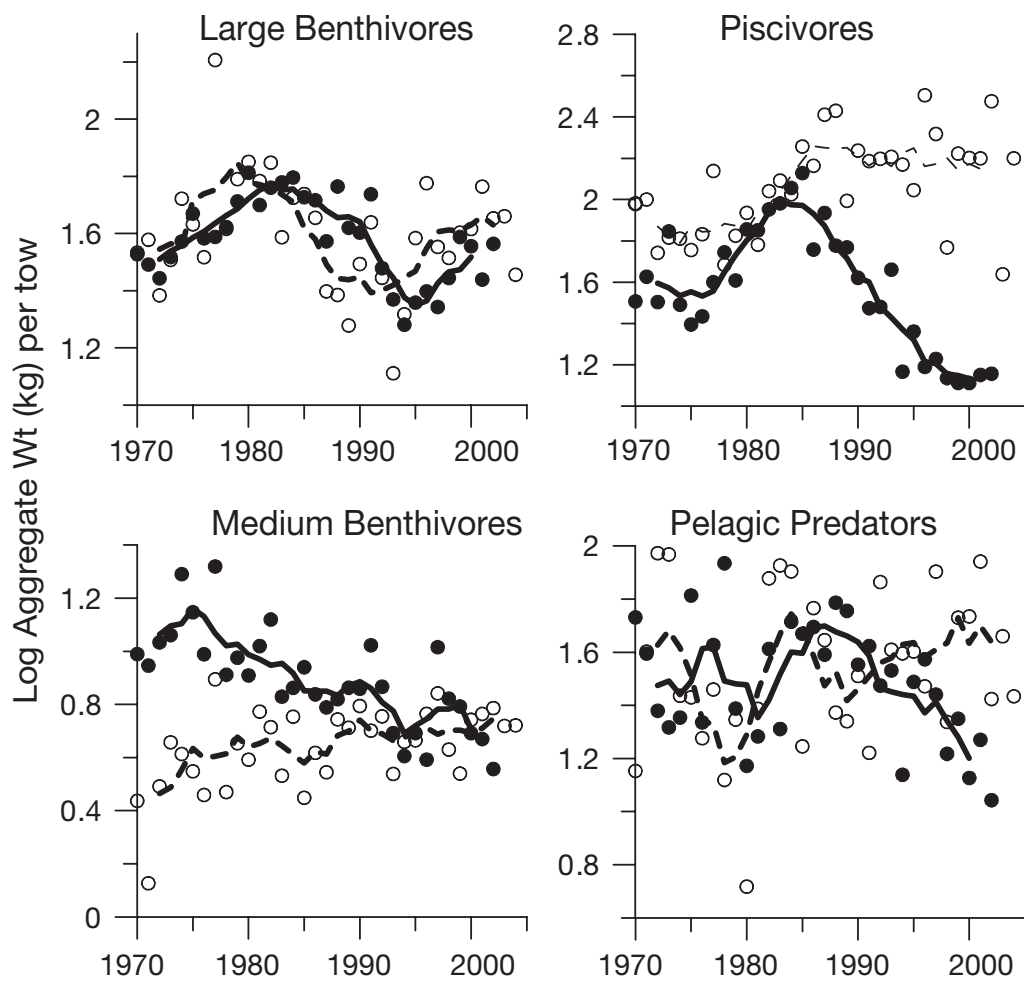

gonus pandionis, summer flounder Paralichthys dentatus, deep water flounder Monolene sessilicauda, spotted wolffish Anarhichas minor, Greenland cod Gadus ogac, barracudina Paralepis coregonoides, spinytail skate Raja spinicauda, polar sculpin Cottunculus micropes, northern puffer Sphoeroides maculates, planehead filefish Monacanthus hispidus, and red dory Cyttopsis roseus. Those species unique to the west were: Atlantic silverside Menidia menidia, blueback herring Alosa aestivalis, frostfish Benthodesmus elongatus simonyi, conger eel Conger oceanicus, lookdown Selene vomer, gray triggerfish Balistes capriscus, pearlsides Maurolicus pennanti, hatchetfish Polyipnus asteroids, clearnose skate Raja eglanteria, small-scale mora Laemonema barbatulum, longnose batfish Ogcocephalus vespertilio, longnose grenadier Coelorhynchus carminatus, fawn cuskeel Lepophidium cervinum, and halfbeak Hyporhamphus unifasciatus. None of the species unique to each region can be considered dominant species-all are relatively rare.
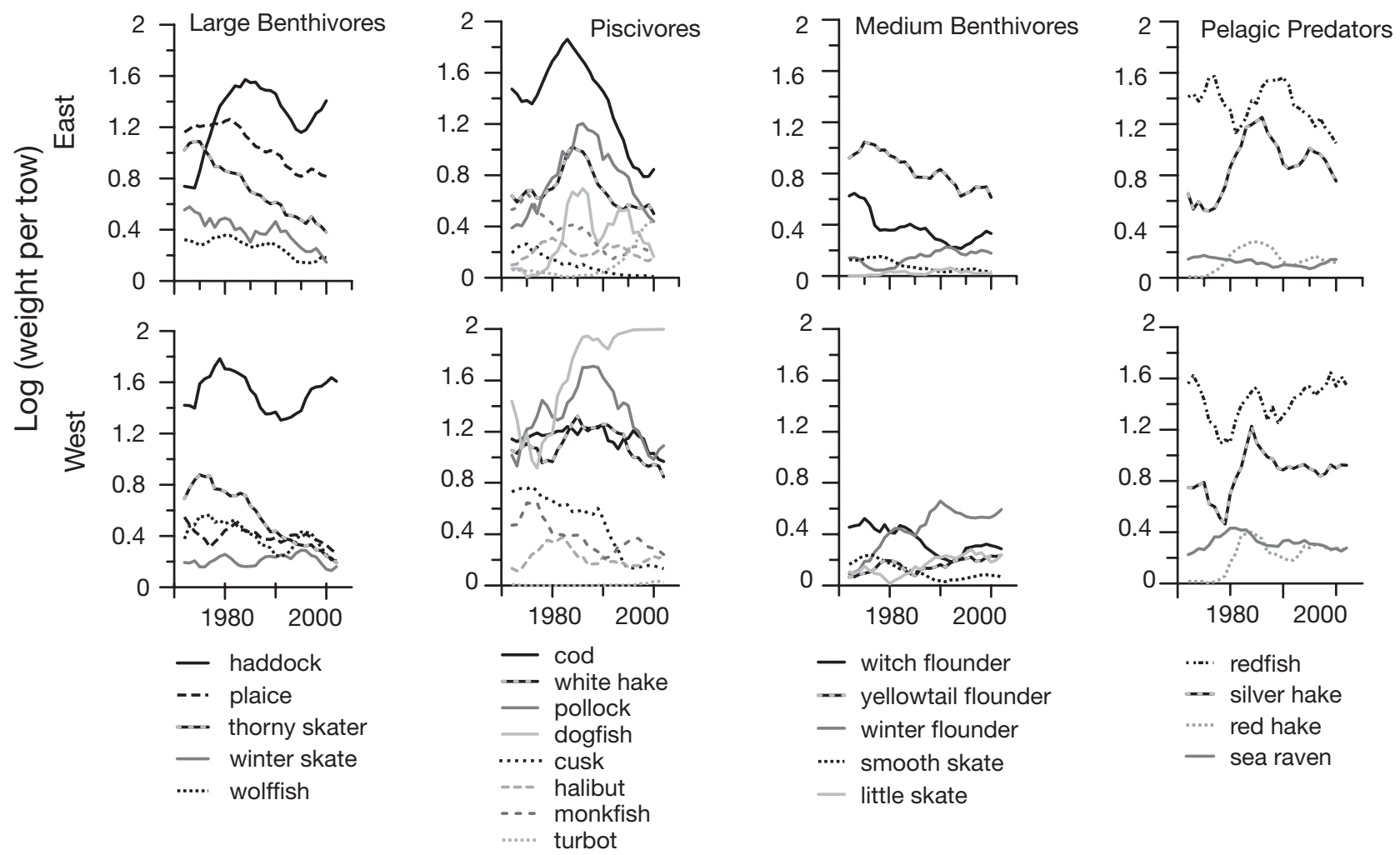

Fig. 5. Log weight (kg) per tow for individual species (see Table 1 for scientific names) within functional groups. Lines represent $5 \mathrm{yr}$ running averages. For clarity, species that comprised $<1 \%$ of the total biomass of the functional group in both the east and west were not plotted 


\section{Condition}

Based on long-term averages, the index of base productivity in the west (1.67 $\mathrm{mg}$ chlorophyll $\left.\mathrm{m}^{-3}\right)$ is $48 \%$ higher than in the east (1.13 $\mathrm{mg}$ chlorophyll $\left.\mathrm{m}^{-3}\right)$, suggesting that the latter area is less productive (Frank et al. 2006). Also, long-term average bottom temperatures in the west $\left(6.5^{\circ} \mathrm{C}\right)$ are warmer than in the east $\left(4.85^{\circ} \mathrm{C}\right)$. If species in the west exhibited a higher condition level than their eastern counterparts, perhaps higher base productivity translates into greater food resources, or a greater resilience to over-fishing; such an effect might transcend any density-dependent effects.

At a functional group level, condition declined in both the east and west for 3 out of 4 groups. Pelagic predators showed no temporal trend (Fig. 6). Condition exhibited a declining trend in 9 out of 18 species where regional effects were minimal (Table 1): condition was additively higher in 3 species in the east (white hake, monkfish, plaice) and in 3 species in the west (redfish, haddock, winter flounder). The interaction term between year and region was significant for 4 species. Cod condition in the east declined over time at a greater rate than in the west $\left(\mathrm{R}^{2}=0.69 ; \mathrm{p}<0.05\right)$. The condition of eastern witch flounder was initially higher, but declined to a level similar to that in the west $\left(\mathrm{R}^{2}=0.65 ; \mathrm{p}<0.05\right)$. The condition of western yel-
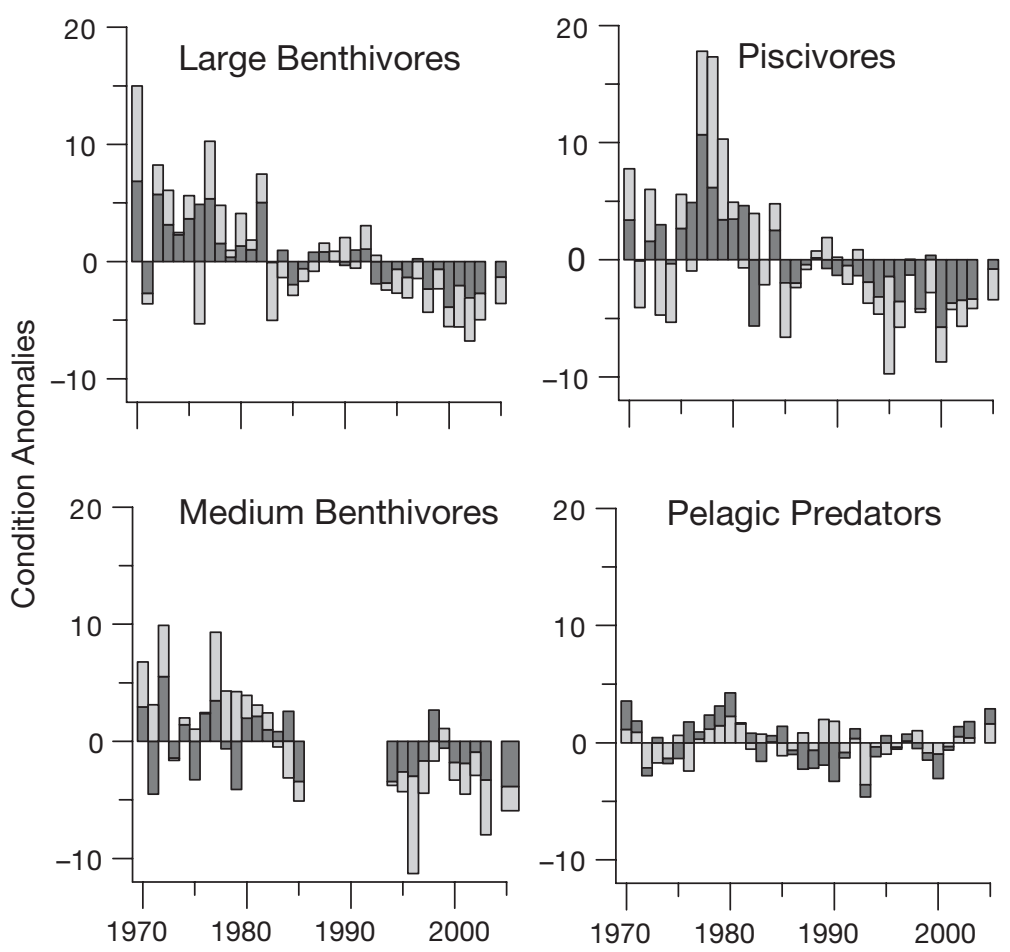

Fig. 6. Bar plot of the sum of condition anomalies for each functional group. Dark bars: eastern Scotian Shelf; light bars: western Scotian Shelf lowtail flounder was initially higher, but declined to a lower level than that in the east $\left(\mathrm{R}^{2}=0.38\right.$; $\left.\mathrm{p}<0.01\right)$. The condition of smooth skate was initially similar between east and west, but declined at a greater rate in the west $\left(\mathrm{R}^{2}=0.24 ; \mathrm{p}<0.05\right)$.

The rate of decline in condition was slower in western cod. There were identical rates of decline, but a higher condition in western haddock, winter flounder, and pollock; redfish had a higher, nearly constant level of condition. As these were the populations characterized by a lesser rate of decline, or showed a compensatory response (Fig. 3), the results offer limited evidence that condition in some way contributes to resilience and the associated patterns we have observed, but it does not appear to be a uniform trait among western species.

\section{Individual growth rate}

Decline in growth rates, as have been observed in many commercial species, translate to a reduction in both somatic and reproductive potential. We used trends in mean size-at-age (average individual growth rate) as an additional measure of population health. Cod, pollock, haddock, and silver hake size-at-age has been consistently assessed over the past 30+ yr. Cod size-at-age has only declined in the east. Haddock size-at-age has declined in the east and, at a lower rate, in the west (Fig. 7). Both cod and haddock are known to exhibit a complex stock structure and have been managed as eastern and western populations. Pollock and silver hake growth rates have declined at the same rate in both the east and west, but these species show limited spatial structuring and have typically been managed at the scale of the entire Scotian Shelf (i.e. east and west combined). In effect, 5 out of 6 populations declined in size-at-age across both regions.

\section{Temporal stability}

Resilience to fishing, in our context, is reflected by a stable aggregate biomass or reversibility, i.e. when fishing is reduced, biomass increases and vice versa. If the biomass of individual species is variable, resilience is reflected by relatively higher levels of compensation. We compared functional group temporal stability (based on Eq. 2, which accounts for spe- 
Table 1. Species contained in each functional group and analysis of covariance summary results for some species. Condition was the response variable and was modeled as a function of region, with year (yr) as a covariate. NA: not applicable; NS: not significant; $\mathrm{Pr}>$ F refers to probability greater than the F-statistic; coeff.: coefficient; SE: standard error; ID: insufficient data for analysis (Result Type refers to 1 of 5 results: [1] no difference between covariate slope within regions, no covariate trend, no region effect; [2] no interaction, parallel horizontal slopes and difference between regions; [3] no interaction, parallel slopes with trend, no difference between regions; [4] no interaction, parallel slopes with trend and differences between regions; [5] covariate slope differed between regions and is reported in text. If the region coefficient for the west was negative [and significant], the east had greater condition, and, conversely, a positive coefficient implies the west had a greater condition [Result Types 2 and 4])

\begin{tabular}{|c|c|c|c|c|c|c|c|}
\hline $\begin{array}{l}\text { Group/ } \\
\text { Species }\end{array}$ & $\begin{array}{l}\text { Scientific } \\
\text { name }\end{array}$ & $\begin{array}{c}\text { Mult. } \\
\mathrm{R}^{2}\end{array}$ & $\begin{array}{c}\text { Factor (region) } \\
\text { coeff. and } \\
\text { SE for west }\end{array}$ & $\begin{array}{c}\text { Factor } \\
\text { (region) } \\
\operatorname{Pr}>F\end{array}$ & $\begin{array}{l}\text { Covariate } \\
\quad(y r) \\
\text { coeff. (SE) }\end{array}$ & $\begin{array}{c}\text { Covariate } \\
\text { (yr) } \\
\operatorname{Pr}>F\end{array}$ & $\begin{array}{c}\text { Result } \\
\text { Type }\end{array}$ \\
\hline \multicolumn{8}{|l|}{ Piscivores } \\
\hline Cod & Gadus morhua & 0.69 & NA & NA & NA & NA & 5 \\
\hline Halibut & Hippoglossus hippoglossus & 0.04 & $-0.005(0.01)$ & NS & $-0.005(0.0005)$ & $<0.05$ & 3 \\
\hline Pollock & Pollachius virens & 0.46 & $0.013(0.012)$ & NS & $-0.005(0.0006)$ & $<0.001$ & 3 \\
\hline White hake & Urophycis tenuis & 0.16 & $-0.027(0.009)$ & $<0.01$ & $-0.0002(0.0004)$ & ) NS & 2 \\
\hline Monkfish & Lophius americanus & 0.11 & $-0.046(0.019)$ & $<0.05$ & $-0.0006(0.0009)$ & NS & 2 \\
\hline Spiny dogfish & Squalus acanthias & 0.16 & $0.00009(0.05)$ & NS & $-0.005(0.002)$ & $<0.05$ & 3 \\
\hline Cusk & Brosme brosme & 0.06 & $0.05(0.04)$ & NS & $-0.002(0.002)$ & NS & 1 \\
\hline Turbot & Reinhardtius hippoglossoides & ID & & & & & \\
\hline \multicolumn{8}{|l|}{ Large benthivores } \\
\hline American plaice & Hippoglossoides platessoides & 0.3 & $-0.03(0.01)$ & $<0.05$ & $-0.003(0.0005)$ & $<0.001$ & 4 \\
\hline Haddock & Melanogrammus aeglefinus & 0.53 & $0.025(0.006)$ & $<0.001$ & $-0.003(0.0003)$ & $<0.001$ & 4 \\
\hline Wolffish & Anarhichas lupus & 0.23 & $-0.002(0.014)$ & NS & $-0.002(0.0006)$ & $<0.001$ & 3 \\
\hline Winter skate & Leucoraja ocellata & 0.07 & $-0.022(0.02)$ & NS & $-0.002(0.001)$ & NS & 1 \\
\hline Thorny skate & Amblyraja radiata & ID & & & & & \\
\hline Ocean pout & Macrozoarces americanus & ID & & & & & \\
\hline Barndoor skate & Dipturus laevis & ID & & & & & \\
\hline Hagfish & Myxine glutinosa & ID & & & & & \\
\hline \multicolumn{8}{|l|}{ Medium benthivores } \\
\hline Winter flounder & Pseudopleuronectes americanus & 0.28 & $0.013(0.12)$ & $<0.001$ & $-0.005(0.006)$ & NS & 2 \\
\hline Witch flounder & Glyptocephalus cynoglossus & 0.65 & NA & NA & NA & NA & 5 \\
\hline Yellowtail flounder & Limanda ferruginea & 0.38 & NA & NA & NA & NA & 5 \\
\hline Little skate & Leucoraja erinacea & 0.07 & $0.003(0.025)$ & NS & $-0.0015(0.001)$ & NS & 1 \\
\hline Smooth skate & Malacoraja senta & 0.24 & NA & NA & NA & NA & 5 \\
\hline Windowpane flounder & Scophthalmus aquosus & ID & & & & & \\
\hline Black dogfish & Centroscyllium fabricii & ID & & & & & \\
\hline \multicolumn{8}{|l|}{ Pelagic predators } \\
\hline Silver hake & Merluccius bilinearis & 0.03 & $-0.016(0.015)$ & NS & $-0.0007(0.007)$ & NS & 1 \\
\hline Redfish & Sebastes sp. & 0.73 & $0.18(0.014)$ & $<0.001$ & $0.00009(0.0007)$ & 7) NS & 2 \\
\hline Sea raven & Hemitripterus americanus & ID & & & & & \\
\hline Red hake & Urophycis chuss & ID & & & & & \\
\hline Long-fin hake & Urophycis chesteri & ID & & & & & \\
\hline Offshore hake & Merluccius albidus & ID & & & & & \\
\hline Fourspot flounder & Hippoglossina oblonga & ID & & & & & \\
\hline
\end{tabular}

cies interactions) to 3 functional group metrics that summarized the previous results: (1) temporal change in biomass (slope of log biomass over time), (2) species evenness (as measured by Hill's N1), and (3) temporal change in condition (slope of condition over time). Our expectations were: (1) that functional group temporal stability would have a wedge-shaped relationship with the temporal change in biomass: low slopes would be associated with high stability and highly negative or positive temporal changes in biomass would be associated with low stability, (2) species evenness would be higher in groups with higher temporal stability, and
(3) no temporal decline in condition would occur in groups with higher temporal stability. While higher community temporal stability (compensation through species interactions) was associated distinctly with 2 functional groups, there was a slight pattern to suggest that those groups showing high temporal stability had lower rates of temporal change (Fig. 8a). Species evenness may have contributed to this pattern (Fig. 8b). Condition declined in all but one functional group (Fig. 8b), but declined at a lower rate for those showing greatest temporal change. Piscivore biomass in the west has shown a great increase, but low temporal sta- 


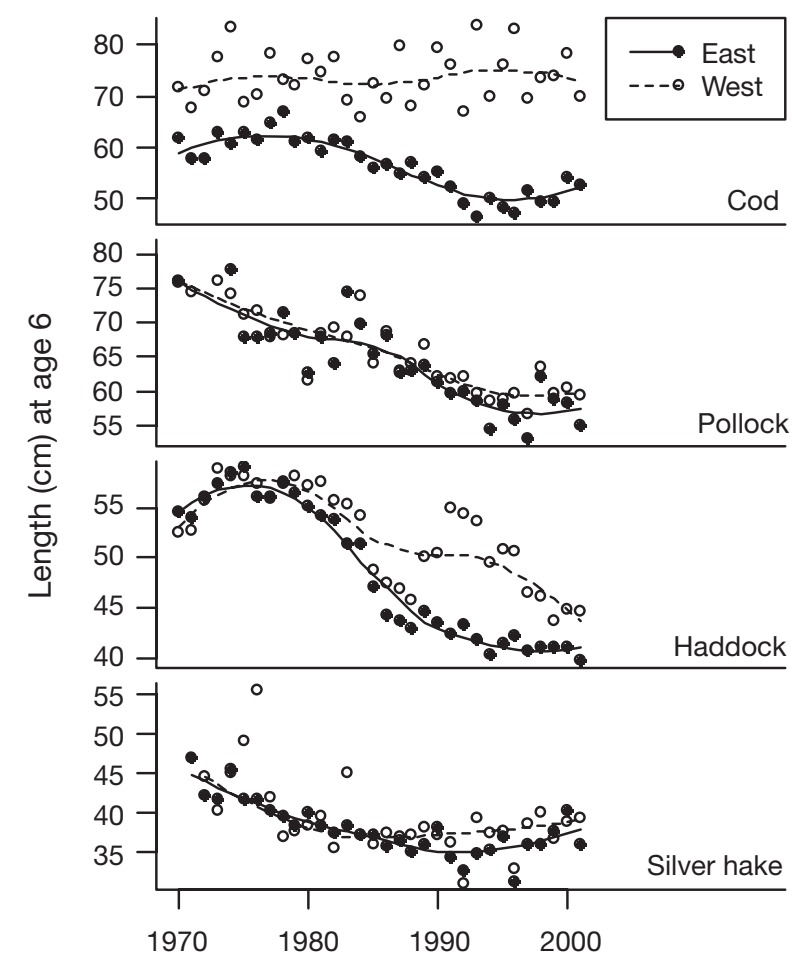

Fig. 7. Growth rate (size-at-age) of cod, pollock, haddock, and silver hake (see Table 1 for scientific names) in each region. $\bullet,-$ - the east; $\mathrm{O},---$ : the west

bility (Fig. 6). This is largely due to 1 species, dogfish. The geographic range of spiny dogfish is concentrated more within the warmer western area. The proportion of dogfish relative to the total biomass of all groundfish in the west has increased since 1970, approaching 0.6 in the past several years. This high proportional increase leads to a growing biomass at the aggregate groundfish level (Fig. 2).

\section{DISCUSSION}

Given the similar exploitation regimes and species composition, it is generally believed that warmer temperature regimes contribute to the apparent resilience of the west relative to the east through increasing growth rates, and thus higher demographic rates (e.g. Zwanenburg et al. 2002). In our initial exploration of differences between regions at the level of the aggregate demersal community, we observed stronger fishing and temperature effects in the east. While fitting smoothed functions has allowed us to explore patterns in biomass, we recognize that it is difficult to capture the effects of fishing and temperature on an aggregate fish community comprised of 29 species of varying life histories. Further, there is the inherent tendency to
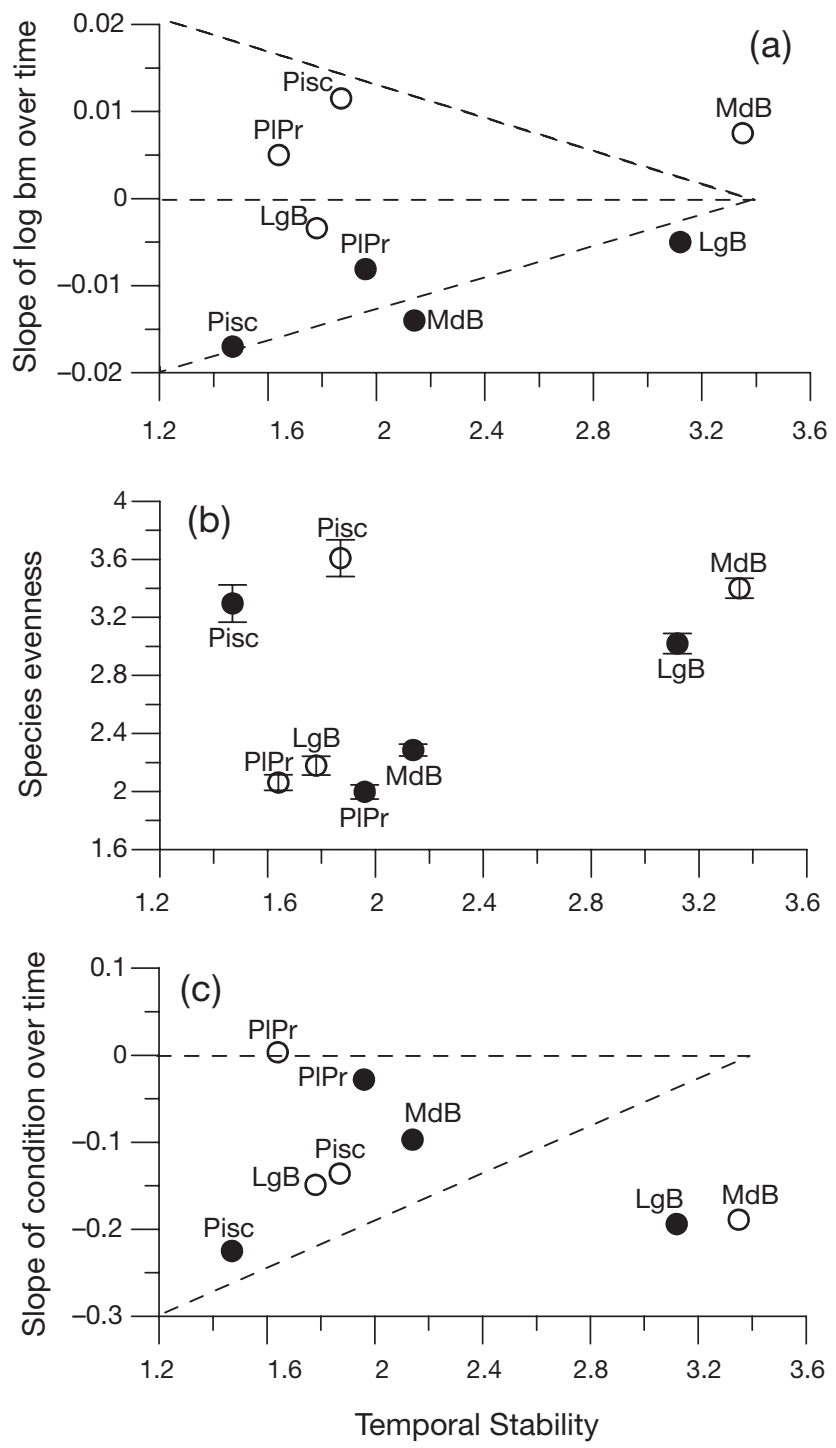

Fig. 8. Temporal stability of functional groups from each region in relationship to: (a) slope of group aggregate biomass (bm) over time, (b) species evenness (Hill's N1), and (c) slope of group aggregate condition anomalies over time. $\bullet$ : the east; O: the west; LgB: large benthivores; Pisc: piscivores; MdB: medium benthivores; PlPr: pelagic predators

over-interpret the significance of the results from GAMs. However, we can infer that the east is more influenced by annual landings, temperature, and individual weight than is the west. The exercise implied that collapsed stocks in the east are not recovering even though fishing has been reduced, perhaps because of the decline in individual weight that has not increased as temperatures have become warmer. It is reasonable to question the proportion of decline in individual weight that is due to size-selective fishing mortality and temperature. That is, individual weight may be an integrator of past temperature and fishing 
regimes. While not the focus of this paper, it would be worthwhile to explore further the decline in size and the implications for recovery.

Aggregate biomass of 4 functional groups on the eastern Scotian Shelf declined (Fig. 8a), but a similar pattern was not evident in the west. In fact, biomass is increasing in most groups in the west. Compensation in the west was due to 1 or 2 species in each functional group: piscivores (spiny dogfish), medium benthivores (winter flounder and yellowtail flounder), and pelagic predators (redfish and silver hake). Interestingly, several of these species were also in better condition in the west. Functional group temporal stability is not higher in the west. There is the possibility that we did not assign the major species to the appropriate functional groups. For example, cod might be considered more of a generalist than a true piscivore. However, whichever classification one might use to assign species to functional groups, it is clear that the west is undergoing rapid changes, as exemplified best by the massive increases in spiny dogfish since 1970.

Recently, ecosystem level indicators of resilience have been developed (e.g. Duplisea \& Blanchard 2005), and compensatory dynamics within trophic levels may define resilience at the ecosystem level (Ernest \& Brown 2001). However, the observed compensation by dogfish populations in the west may not be a stable situation. While not heavily fished until recently in Canadian waters, dogfish are now considered to be overexploited in the United States, and their increase in Canadian waters is largely due to males (NESFC 2003). Spiny dogfish were once considered a highly migratory species, migrating from the southeastern United States coast, along the coast of Nova Scotia in June, and appearing in Newfoundland waters throughout July (Templeman 1944), but it appears their range is contracting. Dogfish cannot be considered a permanent replacement for formerly abundant groundfish.

\section{Large-bodied fishes}

The common decline in both regions of larger demersal teleosts and formerly dominant skate species (Fig. 5) may be partly attributable to differences in generation times, as a result of body size and taxonomy. Elasmobranchs, in general, have lower rates of population growth because of their life histories (Dulvy et al. 2000). Large-bodied species are more vulnerable to fishing because size is correlated with age- and size-at-maturity, longevity, and, ultimately, the intrinsic rate of population growth (for a recent empirical example see Levin et al. 2006). The observed pattern of both eastern and western large-bodied piscivore species is part of a world-wide trend towards over-fishing of top-predators (Pauly et al. 2002). It is of interest, however, that haddock is responsible for the most recent increase in the large benthivore group in both areas, due to exceptionally strong year-classes in 1999 and 2000.

\section{Generation time}

All else being equal, the capacity for growth of a population is reflected in the age-at-maturity, as it relates to generation time (Myers et al. 1997). From the years 1979 to 1985 , the average median age at $50 \%$ maturity for western female cod was 1 yr earlier than for eastern cod, although sizes were comparable (Trippel et al. 1997). High adult mortality from fishing gives western cod a distinct advantage that may have contributed to their relative resilience. Their ability to reproduce, at the same size, 1 yr earlier, would have a compounding effect over time.

Slower population growth rates due to lower temperature may contribute to observed differences between the east and west. Certainly, this could be true for cod. We might further suggest that shorter generation times for all species in the west would lead to greater resilience to fishing pressure. Indeed, pollock in the east matured at a later age than in the west in the 1960s (Beacham 1983a). Yet there is evidence of common ages-at-maturity for a variety of species. Silver hake and American plaice age-at-maturity was similar between areas in the 1960s and 1970s (Beacham 1983a,b). Growth rates during the early 1970s for haddock, pollock, and silver hake in the present study were quite similar between the east and the shelf portion of the west, implying similar individual growth rates. While shorter generation times may explain differences in the resilience of cod populations, it does not necessarily follow that the same is true for other species on the Scotian Shelf. Research on differences in maturation schedules between east/ west populations of more species (other than cod) would contribute greatly to evaluating the role of temperature and species composition in the resilience to overfishing.

\section{Species evenness and identity}

More complex food webs (MacArthur 1955, Neutel et al. 2002) and a greater number of species per unit area may confer greater ecosystem resilience through compensatory dynamics. In this study, the greatest proportion of biomass was accounted for by a few species, and it was these common species that compen- 
sated. There was some evidence that compensation was facilitated by a more equitable distribution of biomass.

As was described earlier, the distinction between east and west management areas was primarily based on historical tagging and inferred migration patterns of cod and haddock. For species with distinct populations, there is the possibility that eastern populations of similar species have been reduced to very low levels and are unable to recover due, for example, to Allee effects (Frank \& Brickman 2000). For species with completely unknown levels of mixing among populations, we cannot discount the interesting possibility that populations whose preferred habitat is currently in the west were contracting because environmental conditions were unfavorable in the east. Within the piscivore group, dogfish was primarily responsible for the observed differences in biomass trends. In Shackell et al. (2005), we observed a density-dependent response in distribution for major species (cod, thorny skate, smooth skate) within the east and within the western regions, and no such response in other species. It is certainly possible that range contractions are occurring in some species. Dogfish increased in both areas up until the start of the cooling trend in the east, and then decreased there. Although a shift in distribution is possible, our belief is that for some species such as dogfish, their major area of concentration is in the west, and they expand into the east during periods of high abundance and favorable conditions. In the medium benthivore group, winter flounder increased in both areas, but at a greater rate in the west. As well, halibut and turbot prefer cooler waters and increased over time on the eastern Scotian Shelf, but not enough to compensate for the declining biomass in this region. Given the differences in temperature regimes, winter flounder, halibut, and turbot, if not heavily fished, may simply take a longer time to compensate in the east. This suggests that various western populations are able to compensate because of higher demographic rates due to temperature. Of those species that compensated or remained stable, a shift in distribution remains a possibility for redfish or silver hake. Their summer distribution includes concentrations on the border between east and west.

There were no overwhelming regional differences in condition, yet there were species-specific differences. Western species that either showed a compensatory response in biomass (redfish, winter flounder) or declined at slower rates (cod, pollock) had higher condition levels than their eastern counterparts. Eastern species that had higher condition (white hake, monkfish, plaice) may prefer the eastern area, yet any compensatory response would be delayed due to temperature effects on demographic rates. Higher base productivity or temperatures may translate to increased resilience, but we can rule out that the west region confers a higher condition index for all groundfish species given the mixed results (Table 1). Instead, the west appears to confer an advantage through higher demographic rates for those species preferring warmer waters.

\section{How resilient is the west?}

Frank et al. (2006) proposed that ecosystem dynamics are generally controlled by base resource levels, but that areas with lower levels of base productivity may become predator-controlled if those predators are heavily fished. Species richness may contribute to stability over a much larger scale than between regions on the same shelf. At shelf scales, it is likely that higher demographic rates and species-preferred ranges are most relevant. The consequence is that warmer temperatures may allow common species to compensate sooner.

Greater demographic rates may allow exploited populations to regenerate following depletion, but not indefinitely. Condition has declined in half of the species evaluated, and growth rate has declined in 5 out of 6 populations across the shelf. Declines in growth rate and condition often covary, and the consequences are lower probability of survival and lower rates of reproduction (Lambert \& Dutil 1997). As early as the 1960s to 1970 s, decline in size and age at sexual maturity were being documented in commercial species across the Scotian Shelf, such as haddock, silver hake, American plaice, cod, and yellowtail flounder. For some species, the decline was not as great in the west as in the east (Beacham 1983a,b). Unfortunately, similar information does not exist for many species during the 1980s/1990s. If fishing removes individuals with the capacity to reach larger sizes, those with a lower capacity to reach larger sizes will remain to reproduce. High adult mortality selects for early maturing, smallsized adults. Such size-selective mortality can change life-history traits, such as age- and size-at-maturity. Because life-history traits are related to the population growth rate, there are demographic consequences including increased vulnerability to harvesting through increased natural mortality (higher costs of reproduction) and shorter life span, as well as causing an imbalance in the trophic size structure (Jennings et al. 2002). Reduction in size-/age-at-maturity in many large-bodied species is commonly observed in heavily exploited ecosystems and is now considered to have a significant genetic component (Conover \& Munch 2002). The potential change in trophic level, as well as the loss of growth and reproductive potential and, ulti- 
mately, the total yield that results from declining size and size-/age-at-maturity, would undoubtedly inhibit recovery.

\section{Controlling exploitation}

Too often we read about collapsed marine ecosystems. In Atlantic Canada, we have a unique area where the groundfish fishery has not yet collapsed. What can be done to forestall a collapse? Cessation of fishing has not resulted in the recovery of depleted large groundfish stocks on the eastern Scotian Shelf or in several other geographic areas of the northwest Atlantic (Shelton et al. 2006). Given the declining condition of a number of species, biological reference points should be even more conservative. Despite similar levels of fishing effort, the proportion of large otter trawlers $(>65 \mathrm{ft}, \sim 19.8 \mathrm{~m})$ was consistently greater in the east $(86 \%)$ than in the west $(32 \%)$ from 1960 to 1990 and during the late 1970s and 1980s. These large, highly efficient boats typically targeted large spawning aggregations on the offshore banks of the eastern Scotian Shelf. In contrast, larger spawning aggregations were unavailable in the western fishery because of a 6 mo seasonal spawning closure on Browns Bank that was implemented in the early 1970s (Halliday 1988). It is possible that the differing fleet composition and fishing practices contributed to the collapse in the east and that this is a topic deserving further study.

Coincident with the wide-spread decline of the large-bodied groundfish stocks was the rapid development of new and emerging directed fisheries. This is part of a global trend referred to as serial depletion where fishers, as predators, move on to a neighboring population or a different species when their target population becomes uneconomical to fish (Pauly et al. 2002, Berkes et al. 2006). In our region, as elsewhere, fishermen started to target other species in the early 1990s, such as monkfish, lumpfish, hagfish, and spiny dogfish, as well as an entirely new suite of benthic invertebrates. The rapid pace of these developing fisheries has outrun the study of their basic biology, and, consequently, management lacks fundamental knowledge about the capacity of the species to sustain exploitation at any level. Furthermore, the role of these species in the ecosystem is unknown. Developing fisheries appear to be impeding the recovery of collapsed cod stocks due to by-catch of cod in many geographic areas throughout the northwest Atlantic (Shelton et al. 2006). While the benefits of reducing fishing mortality to prevent the collapse of the groundfish community on the western Scotian Shelf seem obvious, the proliferation of new and emerging fisheries needs to be addressed.
The year-round closure of the Western/Emerald Banks on the eastern Scotian Shelf has effectively eliminated exploitation since 1993. In the intervening $10+\mathrm{yr}$, the biomass of the local haddock stock has increased slightly, while the numerical abundance (survivorship) has increased 100-fold (Fisher \& Frank 2002). The limited biomass response of haddock is due to a strong reduction in body size (size-at-age). In any event, imposed refugia appear essential to modern fisheries in order to protect juvenile and spawning fish. Further, marine protected areas can diminish effects of size-selective mortality, as well as being much easier to govern with certainty (Baskett et al. 2005).

In summary, compensatory dynamics may contribute to ecosystem resilience, but only if not all species are fished, if size-selective mortality is negligible, and if the level of fishing intensity is appropriate to the average generation time of exploited fish. Expansion of marine refugia is considered an important requirement to meet these objectives. Although the west should be protected for its intrinsic properties, a further motivation is that the west serves as an adjacent source for recolonization of the east. The western region would be an excellent area to experiment with stronger conservation measures.

Acknowledgements. We thank all the dedicated people, and especially Jim Simon, who have worked on the research vessel surveys since 1970. We also thank D. W. Brickman, J. E. Carscadden, and S. Anderson for reading an earlier version of the manuscript, and D. Swain for discussion.

\section{LITERATURE CITED}

Baskett ML, Levin SA, Gaines SD, Dushoff J (2005) Marine reserve design and the evolution of size at maturation in harvested fish. Ecol Appl 15:882-901

Beacham TD (1983a) Variability in size or age at sexual maturity of white hake, pollock, longfin hake, and silver hake in the Canadian Maritimes Area of the Northwest Atlantic Ocean. Can Tech Rep Fish Aquat Sci 1157

Beacham TD (1983b) Variability in size and age at sexual maturity of American plaice and yellowtail flounder in the Canadian Maritimes region of the Northwest Atlantic Ocean. Can Tech Rep Fish Aquat Sci 1196

Berkes F, Hughes TP, Steneck RS, Wilson JA and 11 others (2006) Globalization, roving bandits, and marine resources. Science 311:1557-1558

Bundy A (2005) Structure and functioning of the eastern Scotian Shelf ecosystem before and after the collapse of groundfish stocks in the early 1990s. Can J Fish Aquat Sci 62:1453-1473

Choi JS, Frank KT, Leggett WC, Drinkwater K (2004) Transition to an alternate state in a continental shelf ecosystem. Can J Fish Aquat Sci 61:505-510

Conover DO, Munch SB (2002) Sustaining fisheries yields over evolutionary time scales. Science 297:94-96

Dalgaard P (2002) Introductory statistics with R. SpringerVerlag, New York

Dulvy NK, Metcalfe JD, Glanville J, Pawson MG, Reynolds 
JD (2000) Fishery stability, local extinctions and shifts in community structure in skates. Conserv Biol 14:283-293

Dulvy NK, Freckleton RP, Polunin NVC (2004) Coral reef cascades and the indirect effects of predator removal by exploitation. Ecol Lett 7:410-416

Duplisea DE, Blanchard F (2005) Relating species and community dynamics in an heavily exploited marine fish community. Ecosystems 8:899-910

Ehrlich PR (2000) Human natures: genes, cultures, and the human prospect. Penguin Books Canada Ltd., Toronto

Ernest SKM, Brown JH (2001) Homeostasis and compensation: the role of species and resources in ecosystem stability. Ecology 82:2118-2132

Fisher JAD, Frank KT (2002) Changes in finfish community structure associated with an offshore fishery close area on the Scotian Shelf. Mar Ecol Prog Ser 240:249-265

Frank KT, Brickman D (2000) Allee effects and compensatory population dynamics within a stock complex. Can J Fish Aquat Sci 57:513-517

Frank KT, Petrie B, Choi JS, Leggett WC (2005) Trophic cascades in a formerly cod-dominated ecosystem. Science 308:1621-1623

Frank KT, Petrie B, Shackell NL, Choi JS (2006) Reconciling differences in trophic control in mid-latitude marine ecosystems. Ecol Lett 9:1096-1105

Frank KT, Petrie B, Shackell NL (2007) The ups and downs of trophic control in continental shelf ecosystems. Trends Ecol Evol 22:236-242

Fu C, Mohn R, Fanning LP (2001) Why the Atlantic cod (Gadus morhua) stock off eastern Nova Scotia has not recovered. Can J Fish Aquat Sci 58:1613-1623

Halliday RG (1988) Use of seasonal spawning area closures in the management of haddock fisheries in the Northwest Atlantic. Sci Counc Stud NAFO 12:27-36

Halliday RG, Pinhorn AT (1990) The delimitation of fishing areas in the northwest Atlantic. J Northwest Atl Fish Sci 10:1-51

Hastie TJ, Tibshirani RJ (1990) Generalized additive models. Monographs on statistics and applied probability, Vol 43. Chapman and Hall, London

Heath M (2005) Changes in the structure and function of the North Sea fish foodweb, 1973-2000, and the impacts of fishing and climate. ICES J Mar Sci 62:847-868

Hutchings JA, Reynolds JD (2004) Marine fish population collapses: consequences for recovery and extinction risk. BioScience 54:297-309

Jennings S, Greenstreet SPR, Hill L, Piet GJ, Pinnergar JK, Warr KJ (2002) Long-term trends in the trophic structure of the North Sea fish community: evidence from stableisotope analysis, size-spectra and community metrics. Mar Biol 141:1085-1097

Lambert Y, Dutil JD (1997) Condition and energy reserves of Atlantic cod (Gadus morhua) during the collapse of the northern Gulf of St. Lawrence stock. Can J Fish Aquat Sci 54:2388-2400

Lehman C, Tilman D (2000) Biodiversity, stability and productivity in competitive communities. Am Nat 156:534-552

Levin PS, Holmes EE, Piner KR, Harvey CJ (2006) Shifts in a Pacific Ocean fish assemblage:the potential influence of exploitation. Conserv Biol 20:1181-1190

Link JS, Almeida FP (2000) An overview and history of the food web dynamics program of the Northeast Fisheries Science Center, Woods Hole, Massachusetts. NOAA Tech Mem NOAA-NMFS-NE-159

Lotze HK, Milewski I (2004) Two centuries of multiple human impacts and successive changes in a North Atlantic food web. Ecol Appl 14:1428-1447

Editorial responsibility: Howard Browman (Associate Editorin-Chief), Storebø, Norway
MacArthur R (1955) Fluctuations of animal populations, and a measure of community stability. Ecology 36:535-536

McKenzie RA (1956) Atlantic cod tagging off the southern Canadian mainland. Bull Fish Res Board Can 105

Myers RA, Worm B (2003) Rapid worldwide depletion of predatory fish communities. Nature 423:280-283

Myers RA, Mertz G, Fowlow PS (1997) Maximum population growth rates and recovery times for Atlantic cod, Gadus morhua. Fish Bull 95:762-772

Neutel AM, Heesterbeek JAP, de Ruiter PC (2002) Stability in real food webs: weak links in long loops. Science 296: $1120-1123$

NEFSC (Northeast Fisheries Science Center) (2003) Report of the 37th Northeast Regional Stock Assessment Workshop (37th SAW): Stock Assessment Review Committee (SARC) consensus summary of assessments. NEFSC Ref. Doc. 0316. National Marine Fisheries Service, Woods Hole

Pauly D, Christensen V, Guénette S, Pitcher TJ, Sumaila UR, Walters CJ, Watson R, Zeller D (2002) Towards sustainability in world fisheries. Nature 418:689-695

R Development Core Team (2005) R: a language and environment for statistical computing. R Foundation for Statistical Computing, Vienna. Available at: www.R-project.org

Ruzzante DE, Taggart CT, Cook D (1996) Spatial and temporal variation in the genetic composition of a larval cod (Gadus morhua) aggregation: cohort contribution and genetic stability. Can J Fish Aquat Sci 53:2965-2705

Shackell NL, Stobo W, Frank KT, Brickman D (1997) Growth of cod (Gadus morhua), estimated from mark-recapture data as related to temperature on the Scotian Shelf and adjacent areas. ICES J Mar Sci 54:383-398

Shackell NL, Frank KT, Brickman DW (2005) Range contraction may not always predict core areas: an example from marine fish. Ecol Appl 15:1440-1449

Shelton PA, Sinclair AF, Chouinard GA, Mohn R, Duplisea DE (2006) Fishing under low productivity conditions is further delaying recovery of Northwest Atlantic cod (Gadus morhua). Can J Fish Aquat Sci 63:235-238

Swain DP, Sinclair AF (2000) Pelagic fishes and the cod recruitment dilemma in the Northwest Atlantic. Can J Fish Aquat Sci 57:1321-1325

Templeman W (1944) The life-history of the spiny dogfish (Squalus acanthias) and the Vitamin A values of dogfish liver oil. Fisheries Research Bulletin No. 15, 1-102. Newfoundland Department of Natural Resources

Trippel EA, Morgan MJ, Frechet A, Rollet C, Sinclair A, Annand C, Beanlands D, Brown L (1997) Changes in age and length at sexual maturity of Northwest Atlantic cod, haddock and pollock stocks, 1972-1995. Can Tech Rep Fish Aquat Sci 2157:xii + 1-120

Ward P, Myers RA (2005) Shifts in open-ocean fish communities coinciding with the commencement of commercial fishing. Ecology 86:835-347

Ware DM, Thomson RE (2005) Bottom-up ecosystem trophic dynamics determine fish production in the Northeast Pacific. Science 308:1280-1284

Zwanenburg KCT, Bentzen P, Wright JM (1992) Mitochondrial DNA differentiation in western north Atlantic populations of haddock (Melanogrammus aeglefinus). Can J Fish Aquat Sci 49:2527-2537

Zwanenburg KCT, Bowen D, Bundy A, Drinkwater K, Frank K, O'Boyle R, Sameoto D, Sinclair M (2002) Decadal changes in the Scotian Shelf large marine ecosystem. In: Sherman K, Skjoldal HR (eds) Large marine ecoystems of the North Atlantic: changing states and sustainability. Elsevier Science, Amsterdam, p 105-150

Submitted: August 9, 2006; Accepted: February 28, 2007

Proofs received from author(s): April 18, 2007 